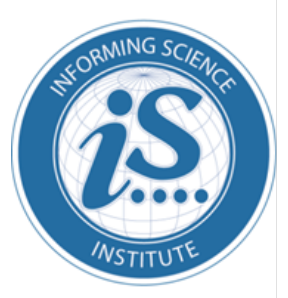

Proceedings of the Informing Science + Information Technology Education Conference

An Official Publication

of the Informing Science Institute

InformingScience.org

InformingScience.org/Publications

June 30 - July 4, 2019, Jerusalem, Israel

\title{
Usage Habits in Music Streaming ApPLICATIONS AND THEIR INFLUENCE ON PRIVACY RELATED ISSUES [RESEARCH IN PROGRESS]
}

Maor Weinberger*

Dan Bouhnik

* Corresponding author
Bar-Ilan University, Ramat-Gan, Israel

Jerusalem College of Technology, Jerusalem, Israel maor89@gmail.com

bouhnik@jct.ac.il

\section{ABSTRACT}

Aim/Purpose In this exploratory study we examine personal information management within music streaming applications. Also, we investigate the sense of ownership over songs being played on music streaming applications and whether the use of these services may be considered a social activity. In a later stage, we intend to test privacy related issues in music streaming applications and the factors that influence privacy concerns when using these services.

Methodology This is examined by using a mixed methodology and consists of two phases: qualitative and quantitative. The qualitative stage includes semi-structured interviews with 10 music streaming application users in order to explore the possible change in personal information management, following the emergence of these applications (e.g. change in classification methods and song retrieval methods). The quantitative phase includes the distribution of closed ended questionnaires among 200-250 users of music streaming applications, aiming to explore personal information management issues and privacy related issues that emerge while using these applications (e.g. privacy concerns). Currently, a pilot of the qualitative stage was issued.

Findings We found that users still rely on traditional methods of personal information management, rather than making use of the newer features available by the innovative music streaming applications. The same applies to the use of these applications as part of a social activity. In addition, it seems that the emergence of music streaming applications influenced the sense of ownership over songs in personal music libraries and made it ambiguous among music consumers.

[Accepting Editor: Eli Cohen | Received: (date) | Revised: (date) | Accepted: (date). Cite as: author. (2019). Usage habits in music streaming applications and their influence on privacy related issues. Proceedings of the Informing Science and Information Technology Education Conference, Jerusalem, Israel, pp. 437-447. Santa Rosa, CA: Informing Science Institute. https://doi.org/10.28945/4272

(CC BY-NC 4.0) This article is licensed to you under a Creative Commons Attribution-NonCommercial 4.0 International License. When you copy and redistribute this paper in full or in part, you need to provide proper attribution to it to ensure that others can later locate this work (and to ensure that others do not accuse you of plagiarism). You may (and we encourage you to) adapt, remix, transform, and build upon the material for any non-commercial purposes. This license does not permit you to use this material for commercial purposes. 
Usage Habits in Music Streaming Applications and Their Influence on Privacy Related Issues

Contribution As far as we know, this is the first academic research to investigate the issue of personal music management among music streaming applications and the also the first to use a mixed methods approach to examine digital music consumption. In addition, it is the first study that takes into account privacy related issues among the users of music streaming applications.

Keywords music streaming applications, personal information management, privacy, personalization

\section{INTRODUCTION}

The digital age revolutionized the face of the music industry (Cohen, 2010). As in the past, the creation, duplication and distribution of musical libraries was the exclusive purview of professionals, however presently any person with a basic knowledge of computers and an internet connection can do the same. Today, users can obtain, legally or otherwise, any musical item ever recorded. In addition, they can store, organize and copy them as many times as they want, and also distribute them quickly to whomever they wish (Cohen, 2010; Stafford, 2010).

The digital revolution changed the model of music consumption: it dispensed with the need to rely on the whims of traditional musical media (radio, television and the like) and created an additional and more advanced option for the consumption of music, one that no longer required the physical or digital possession of music items (Cohen, 2010). Today, music can be consumed directly and at any time via digital streaming services. These services have massive music collection databases, and mostly operate online, allowing users to listen to music whenever they wish (Aguiar \& Martens, 2016; Swanson, 2013). Furthermore, streaming services allow listeners to create and manage their own playlists and even share them with their friends (Nguyen, Dejean, \& Moreau, 2014; Snelson, 2011). Dozens of music streaming services exist, each one offering users its own unique qualities and functions. These are application services, mostly web-based, using a client-server model which allows a user to select music items on demand from a music database (Kreitz \& Niemelä, 2010). Although most streaming applications do maintain intellectual property agreements with artists and songwriters to provide them their legally deserved royalties, they are often being criticized of being insufficient (Nguyen et al., 2014; Swanson, 2013).

The emergence of these services also influenced the personal information management of users. Personal information management is defined as "the activities a person performs in order to acquire or create, store, organize, maintain, retrieve, use and distribute the information needed to meet life's many goals" (Jones, 2008, pp. 5). These items may be physical - documents, books, letters, etc. - or digital: files, favorites and digital folders. In terms of the management of music information, in the past users classified their physical or digital collections according to criteria such as artist name, song name, music genre, etc. However, when it comes to streaming services, it is possible that new ways have emerged for the management of music consumed (Hagen, 2015) - piling vs. filing (Malone, 1983), or to information retrieval methods - searching vs. browsing (Marchionini, 1997). In addition, music streaming services and applications allow users to shape the setting from which they consume their music to match their own preferences. For example, music streaming applications encourage the creation of individual music playlists that can adjusted to specific moods (Hagen, 2015). Those may be implemented in context-aware systems, such as of smart-homes (Mahroo, Spoladore, Caldarola, Modoni, \& Sacco, 2018).

However, as new and diverse possibilities emerge for the personalization of music information within streaming applications and services, it increases the risk for personal privacy. Privacy has always been a major concern associated with the commercial information technology, and particularly with regard to the issue of personalization (Sutanto, Palme, Tan, \& Phang, 2013) - "the ability to provide content and services that are tailored to individuals based on knowledge about their preferences and behaviors" (Adomavicius \& Tuzhilin, 2005). The tradeoff between online privacy and self-disclosure 
was investigated in past studies (Fogel \& Nehmad, 2009; Hoy \& Milne, 2010; Milne, Rohm, \& Bahl, 2004; Paine, Reips, Steiger, Joinson, \& Buchanan, 2007; Taddicken, 2014; Weinberger \& Bohnik, 2018; Weinberger, Bouhnik, \& Zhitomirsky-Geffet, 2017; Wills \& Zeljkovic, 2011), some of which focused specifically on the tradeoff between online personalization and online privacy protection (e.g., Weinberger \& Bouhnik, 2018). Many of the studies showed that users are concerned with their online privacy and wish to protect it (e.g., Paine et al., 2007; Wills \& Zeljkovic, 2010). Nevertheless, it was found that they tend to forfeit their privacy as long as it benefits them (Awad \& Krishnan, 2006; Chellappa \& Sin, 2005; Sheng, Nah \& Siau, 2005). This kind of behavior is consistent with the phenomenon termed the "privacy paradox" - a miscorrelation between users' privacy attitudes and actual behavior (Barnes, 2006; Norberg, Horne, \& Horne, 2007) and is explained by the "Uses and Gratification Theory" - a lack of willingness to forfeit the benefits of information disclosure, e.g., social benefits (Debatin, Lovejoy, Horn, \& Hughes, 2009; Trepte et al., 2015).

In this study, we will examine the manifestation of personal information management within music streaming applications, focusing on methods of information retrieval. In addition, we will strive to find whether there is still a sense of ownership over songs being played on music streaming applications and whether the use of those services may be considered a social activity. In a later stage, we will test privacy related issues in music streaming applications, such as intellectual property rights, and the factors that influence privacy concerns in using these services.

As far as we know, this is the first academic research to investigate the issue of personal music management among music streaming applications and the also the first to use a mixed methods approach to examine digital music consumption. In addition, it is the first study that takes into account privacy related issues among the users of music streaming applications.

\section{RELATED WORK}

Three scopes of literature will be discussed: first, we will provide a general overview of notable events in the history of music consumption; second, we will put music information management in the context of personal information management; third, we will provide a detailed discussion of privacy issues with regard to personalization in music streaming services and applications.

\section{HISTORICAL BACKGROUND}

The technological development with the greatest influence on the global music industry was the invention of recording technology in 1877. For the first time, music consumers could save, transfer and replicate sounds produced elsewhere. Until the end of the nineteenth century, sound recording was primarily used for speech and rarely for music. Two major systems for sound recording had been invented: Thomas Edison's phonograph, which could both record and play sound and Emil Berliner's gramophone which used a record - a flat, round disc with a hole in its middle. The record allowed the mass production of sound recordings, and enabled music consumers to play music on household devices. In the first half of the twentieth century, the tape recorder and audio cassette were invented. These two technologies allowed music to be recorded at home and facilitated the cheap and easy reproduction of musical content, in addition to allowing playback of a cassette's contents. These innovative possibilities opened the door for the mass distribution of music content worldwide. The audiocassette allowed easy fast-forwarding and rewinding and provided the user a large degree of control over the order of her music playback. However, the listener still lacked total control over the song playlist (Malm, 1992).

The year of 1983 marked the beginning of the digital age of music with the invention of the compact disc $(\mathrm{CD})$. The $\mathrm{CD}$ offered a more convenient listening experience, and a higher sound quality without precedent. It was also a far better storage system than its predecessors. However, its mechanics were still like those of an audio cassette. Its advantage lay in the ability to create personal music 
collections and to copy these with ease. Its greatest disadvantage, was the inability to control playing order, even though one could skip or replay tracks (Malm, 1992; Swanson, 2013).

In the eighties and nineties of the previous century, the music industry thrived and was flooded with content. Artists made a fortune as listeners who wanted to listen to a specific song had to buy the whole album in which it was played (single albums were also available for purchase, however they were not as common). This all changed in the early nineties, with the advent of the computer revolution and the beginning of MP3 use. The digital revolution and the beginning of home internet use served as the background for MP3 use. Like all files, MP3 files could be sent via email or shared online. Likewise, files could be downloaded via dedicated service plans. An example is Napster-a service which was based on peer-to-peer sharing. Napster was founded in 1999, and became one of the first services to allow the sharing and exchange of MP3 files on a large scale and for free. Following the establishment of such services, new options emerged such as: unlimited access to musical items for free; a certain degree of ownership (albeit illegal) of the songs downloaded to the user's computer; and the ability to manage personal music collection in a variety of ways. Those advanced options inaugurated a substantial revolution in the music industry, especially the music business (Denegri-Knott \& Tadajewski, 2010; Swanson, 2013).

In 2002, the possibilities of music consumption developed even further, with the establishment of online music services based on media streaming technology. This technology allowed a user to play audio, video or multimedia files through the internet via a direct, simultaneous and real-time transfer. Streaming files could be used the moment their data was received and saved on the receiving station (for example, the service providing them). It became unnecessary to physically download the files onto the user's computer and the songs left no hard copies. It is important to note that such services are careful to maintain the high technical quality of their contents (Nguyen et al., 2014; Snelson, 2011).

There are, today, a number of different streaming services; we will focus on music streaming applications (e.g., Spotify, Soundcloud and TuneIn). These applications were established as personal radios, expanding regular media channels. Instead of the user listening to a predetermined playlist chosen by a higher authority, these services allow the listener to choose for himself how to manage and share content (Nguyen et al., 2014; Snelson, 2011). Notably, as opposed to the old peer-to-peer sharing platforms like Napster that allow an illegal consumption of music, the larger and well-known applications (such as Spotify) do maintain intellectual property agreements with artists and songwriters to provide them their legally deserved royalties. However, many of them complain that they are insufficient (Nguyen et al., 2014; Swanson, 2013).

\section{MUSIC STREAMING APPLICATIONS AND PERSONAL INFORMATION MANAGEMENT}

The emergence of music streaming applications also influenced the personal information management of music information, i.e. song tracks, albums and playlists. Malone (1983) claimed that there are two main classification methods: files and piles. In the past, users classified their physical or digital collections according to traditional criteria such as artist name, song name, music genre, etc., however in streaming applications new ways have been introduced for music information management (Hagen, 2015). For example, music streaming applications encourage the creation of individual music playlists that are not dependent on specific genre or artist or context sensitive playlists that are adjusted to daily situations and routines, such as: playlists for exercise, for falling asleep or moodspecific. In the context of personal information management and Malone's (1983) theory, this classification method is closer to the piling than to filing, as there is no orderly method of file arrangement. Notably, as in most streaming services there is no obligation that the media file will be stored upon the platform of usage (e.g. smartphone), the files do not remain under the users' ownership (Morris \& Powers, 2015). Thus, users take personal information management of these files in a different perspective. 
In addition, according to McCourt (2005), digital technologies offer more possibilities to modify and alter original content in ways that stress out users' different desires:

- The desire for compacting - the ability to contain vast amounts of data within small areas.

- The desire for immediacy - the ability to sort files easily to transform the listening experience.

These desires are manifested in the creation of playlists, as McCourt (2005) argues that "in cyberspace, people collect lists rather than objects". Kibby (2009) describes digital playlists as the replacements of homemade mix-tapes, common at the 1980s. They act as a form of self-expression and fulfill another desire mentioned by McCourt - the desire for customization. The malleability of digital media allows users to customize their listening environment in an efficient way. This desire is reflected by the fact digital music services allow users to shape the setting from which they consume their music to match their own preferences. However, as new and diverse possibilities emerge for the personalization of music information within streaming applications and services, it increases the risk for personal privacy.

\section{PRIVACY ISSUES AND PERSONALIZATION}

Proactive specification of the user's products and services is called "customization" (Li \& Unger, 2012). This uniquely-shaped online environment serves as a digital fingerprint that might be exploited by external parties in order to expose users' identities (Eckersley, 2010; Mayer, 2009). One of the most common methods for online surveillance is the tracking cookie. Cookies were initially developed to allow users to re-visit websites without the need to identify themselves and their preferences each time. However, in subsequent years cookies have been used in other ways, including in personalization processes (Millett, Friedman, \& Felten, 2001). Personalization is used many times by a commercial entities, offering customers products and services that best suit them, based on previously collected data (Li \& Unger, 2012). This method may benefit both the consumer and the vendor, however cookies that enable personalization might also be used in ways that invade users' privacy, for example third party websites use cookies to create user profiles without their knowledge and track users' online activities (Millett et al., 2001; Milne, 2000).

As customization and personalization are closely related terms and particularly in relation to privacy issues, in this work, both will be referred to as "personalization".

Past research showed that even though personalization has a positive effect, privacy concerns negatively affect users' intention to use it (Awad \& Krishnan, 2006; Chellappa \& Sin, 2005; Li \& Unger, 2012; Sheng, Nah, \& Siau, 2008; Sutanto et al., 2013). However, it seems that the impact of these concerns may be limited, as users may relinquish their personal privacy, in return for the various benefits gained from using personalized services (Hann, Hui, Lee, \& Png, 2002). The tradeoff between online personalization and privacy protection is a widely explored topic in the context of electronic commerce for many years (Awad \& Krishnan, 2006; Chellappa \& Sin, 2005; Goodwin, 1991; Lee \& Letho, 2010; Lee \& Rha, 2016; Li \& Unger, 2012; Milne \& Gordon, 1993; Sheng et al., 2008; Sutanto et al., 2013; Xu, Lou, Carroll, \& Rosson, 2011). Many studies which explored this topic came to the conclusion that in order for the users to agree to online personalization, its benefits must outweigh the potential risks to their privacy (e.g., Awad \& Krishnan, 2006; Chellappa \& Sin, 2005; Sheng et al., 2008). Nevertheless, users' preference in this tradeoff remains inconsistent. As Awad \& Krishnan (2006) found, privacy concerns significantly affect users' agreement to personalized advertising. Also, Turow, King, Hoofnagle, and Bleakley (2009) found that most Americans do not want marketers to personalize their advertisements according to their interests. However, Xu et al. (2011), found that personalization could, in some cases, overcome users' privacy concerns. Likewise, Li \& Unger (2012) found that the acceptance of personalization can overcome privacy concerns as long as it is perceived by the user as qualitative. 


\section{METHODOLOGY}

This study will be conducted using mixed methodology of Exploratory Sequential Research, in which the data collection at the qualitative phase precedes the data collection at the quantitative phase (Creswell, 2014). In both phases, the data would be collected in a reactive manner; that is, at the qualitative phase - using semi-structured interviews and at the quantitative phase - using closed-ended questionnaires.

In the first phase, we have initiated a pilot using hour long semi-structured interviews with three users of music streaming applications in order to learn more about the possible change in personal information management, following the emergence of these applications (e.g., the change in song retrieval process). The interviewees are students in Bar-Ilan University, who have used music streaming applications for at least one year. The main question we sought to clarify in this phase was: whether personal information management is manifested in the use of music streaming services and if so, how? The primary questions used during the interviews to clarify the study's main question mentioned above are presented herewith:

1. What are the user's listening habits?

2. How did users retrieve songs before they began using a streaming service as opposed to afterwards?

3. How does the user add new songs to a streaming service?

4. Does the user feel that he or she is the owner of the songs accessed on the streaming service?

5. Can listening to music on a streaming service constitute a form of social activity? If sohow?

Notably, the questionnaire used for the interviews contained pre-prepared questions (as mentioned above). However, during interviews new questions were added based on the answers provided by the participants.

Table 1 below presents the demographic characteristics of the pilot sample.

Table 1: Demographic Characteristics of the pilot $(\mathbf{N}=3)$

\begin{tabular}{|c|c|c|c|}
\hline & A. M. & H. G. & H. R. \\
\hline Gender & Male & Female & Male \\
\hline Age & 28 & 31 & 25 \\
\hline Birthplace & Israel & Israel & Israel \\
\hline Degree & B.A. & M.A. & B.A. \\
\hline Occupation & $\begin{array}{l}\text { Computer depart- } \\
\text { ment in a marketing } \\
\text { company }\end{array}$ & $\begin{array}{l}\text { Content Manage- } \\
\text { ment }\end{array}$ & $\begin{array}{l}\text { Productions and } \\
\text { financial supervisor } \\
\text { at a music center }\end{array}$ \\
\hline
\end{tabular}

This stage will be expanded to include 10-15 interviews in total. Data collected during the interviews will be analyzed using thematic analysis approach, a process for encoding qualitative information. The thematic analysis will be used to establish the quantitative tools of the second phase.

In the second phase, we will distribute an online closed ended questionnaire among 200-250 users of music streaming applications, which aim to explore personal information management issues and privacy related issues that emerge while using these applications (e.g., privacy concerns and intellectual property rights). 


\section{RESULTS}

The first question addressed users' music listening habits and the use of music streaming applications. Two participants mentioned listening to albums, whether bought or downloaded to their computer. These same participants also mentioned listening to music on a music player or through their flash drive. In addition, all three use music streaming applications. They mentioned that they use free services, though one participant mentioned using a paid service in the past. One participant mentioned using only streaming applications and "YouTube". Regarding the types of applications used, all three reported use of "SoundCloud" and at two used "YouTube" and "TuneIn". Additional applications mentioned included: "Pandora", "Shazam" and "Spotify" — using an American access point. The reasons for using those applications were diverse: the wide selection of songs with various listening options; access to songs through personalized recommendations; convenience; and availability without advertisements (for certain services).

Regarding song retrieval process before and after the use of music streaming applications, it was found that in the past the participants would retrieve songs in one of the following ways: two mentioned downloading; one mentioned purchasing albums and cassette tapes, adding that today he continues to do so primarily for collecting purposes and for playing in his car. Likewise, he explained the experience and habit of buying a new album "it became a habit, and I loved opening the wrapping and reading" (A.M.). Another participant mentioned listening to cassettes and to YouTube on the computer. Another, mentioned retrieving songs through various forums and via Google searches. She also mentioned that the TV Music channels, MTV and VH1, helped her to be become familiar with new songs.

All mentioned that their retrieval methods have changed over time. Each participant interpreted this change differently and we therefore received diverse answers. Changes mentioned included: proactive searches using dedicated options within the streaming applications they use. The searches include: song name, artist or album; music recommendations provided by the streaming applications based on the users' consumption habits; more general forms of retrieval of an artist or song through Google: "I use Google to search for lyrics, artist information and an artist's page" (H.G.). One participant mentioned the physical aspect - as in the past he would go to stores themselves to retrieve songs, today he retrieves songs using the streaming services themselves: "You don't need to move a foot, or leave home" (H.R.).

As for the manner of adding new songs to the personal user's collection, the following methods were mentioned: searching for a song after hearing it on the radio; song recommendations offered by the streaming application, based on user's preferences; notifications from the application about new songs by artists that the user "follows"; checking Facebook and dedicated websites (such as www.billboard.com).

When asked about the sense of ownership over songs within the streaming applications, the participants were divided. The first participant claimed that he feels that his song collection does belong to him, at least temporarily. The second claimed that she does not feel like she owns a musical collection, noting that she is dependent on wireless internet. However, the third participant argued that the services he uses: "Spotify" and "Pandora", make him feel a certain ownership, as his song library is concentrated in one place and accessible for him at any time. In addition, he can create playlists and control the order of their play (using a smartphone).

The last question addressed the potential of using music streaming applications to be part of a social activity. All argued that these applications can be used for social activity, as some of them (e.g. "Spotify") contain a toolbar showing the songs that are presently being listened to by their friends, and allow the users to send their friends songs and messages. In addition, the participants mentioned in this context the option of commenting on songs that are being played: "when someone comments on someone else [within a song comment log], it is super exciting to see the comments" (H.G). 


\section{DISCUSSION AND CONCLUSIONS}

In this study we examined personal information management within music streaming. In addition, we sought to find whether there is still a sense of ownership over songs being played on music streaming applications and whether the use of those services may be considered a social activity.

In terms of music information retrieval, it seems that the users have yet to completely abandon their old habits, even while using music streaming applications. They continue to use the traditional retrieval methods, such as Google searches, even while there are a more targeted options for retrieval within those applications (e.g. search by specific track or lyrics). Putting in the context of information retrieval theories, these proactive and targeted searches may indicate reliance on searching methods rather on browsing methods (Marchionini, 1997).

The use of old-fashioned methods also applies to adding new songs, as users exploit non-streaming media channels, such as Facebook and the radio in order to discover new songs, rather than using the streaming apps recommendations.

In addition, the sense of ownership over the songs has changed with the emergence of music streaming applications and became vague. It seems that it is dependent on two conditions: 1) payment - a sense of ownership exists as long as there is a possibility of paying for songs on a streaming service, which is parallel to buying a physical album; 2) Internet connection - the sense of ownership persists as long as one can listen to songs without the need of Internet connection (an offline mode). However, an offline mode is often available to premium users who pay for using streaming services, so these conditions may be related.

As for the use of music streaming services for social activity, we can conclude that the more a service operates as a social network (e.g., Facebook), the greater the potential for it to be used for social activity. As mentioned in the previous studies, streaming services allow listeners to create and manage their own playlists and to share them with their friends (Hagen \& Lüders, 2016; Nguyen et al., 2014; Snelson, 2011). This, in practice, makes the services more socially oriented. Furthermore, it seems that the users prefer to use streaming services for the purposes they were originally designed for. That is, they distinguish social networks, intended for social activity, from a music streaming service which is intended for playing music. As far as they are concerned, the social options offered on streaming services, are only that - "options". If they do wish to engage in some kind of online social activity, they prefer to do so on a traditional social network.

Notably, all the above only represent a part of the first phase of this research. The second phase, should apply a quantitative method aiming: first, to corroborate the findings of the qualitative phase and second, to investigate an entirely different aspect and test privacy related issues in music streaming applications and the factors that influence privacy concerns in using these services.

\section{REFERENCES}

Adomavicius, G., \& Tuzhilin, A. (2005). Personalization technologies: A process-oriented perspective. Communications of the ACM, 48(10), 83-90. https://doi.org/10.1145/1089107.1089109

Aguiar, L., \& Martens, B. (2016). Digital music consumption on the Internet: Evidence from clickstream data. Information Economics and Policy, 34, 27-43. https://doi.org/10.1016/i.infoecopol.2016.01.003

Awad, N. F., \& Krishnan, M. S. (2006). The personalization privacy paradox: An empirical evaluation of information transparency and the willingness to be profiled online for personalization. MIS Quarterly, 30(1), 1328. https://doi.org/10.2307/25148715

Barnes, B. S. (2006). A privacy-paradox: Social networking in the United States. First Monday, 11(9). https://doi.org/10.5210/fm.v11i9.1394 
Chellappa, R. K., \& Sin, R. G. (2005). Personalization versus privacy: An empirical examination of the online consumer's dilemma. Information Technology \& Management, 6(2-3), 181-202. https://doi.org/10.1007/s10799-005-5879-y

Cohen, A. M. (2010). Music appreciation 2.0: to store or to stream? The Futurist, 44(5), 6-7.

Creswell, J. W. (2014). Research design: Qualitative, quantitative, and mixed methods approaches. Thousand Oaks, CA: SAGE Publications. https://doi.org/10.5539/elt.v12n5p40

Debatin, B., Lovejoy, J. P., Horn, A. K., \& Hughes, B. N. (2009). Facebook and online privacy: Attitudes, behaviors, and unintended consequences. Journal of Computer-Mediated Communication, 15(1), 83-108. https://doi.org/10.1111/j.1083-6101.2009.01494.x

Denegri-Knott, J., \& Tadajewski, M. (2010). The emergence of MP3 technology. Journal of Historical Research in Marketing, 2(4), 397-425. https://doi.org/10.1108/17557501011092466

Eckersley, P. (2010). How unique is your web browser? In M. J. Atallah \& N. J. Hopper (Eds.), Privacy Enhancing Technologies, 10th International Symposium (PETS' 2010): Vol. 6205. Lecture Notes in Computer Science (pp. 118). Berlin, Heidelberg: Springer-Verlag. https://doi.org/10.1007/978-3-642-14527-8 1

Fogel, J., \& Nehmad, E. (2009).Internet social network communities: Risk taking, trust, and privacy concerns. Computers in Human Behavior, 25(1), 153-160. https://doi.org/10.1016/i.chb.2008.08.006

Goodwin, C. (1991). Privacy: Recognition of a consumer right. Journal of Public Policy \& Marketing, 10 (1), $149-$ 166. https://doi.org/10.1177/074391569101000111

Hagen, A. N. (2015). The playlist experience: Personal playlists in music streaming services. Popular Music and Society, 38(5), 625-645. https://doi.org/10.1080/03007766.2015.1021174

Hagen, A. N., \& Lüders, M. (2016). Social streaming? Navigation music as personal and social. Convergence: The International Journal of Research into New Media Technologies, 23(6), 643-659. https://doi.org/10.1177/1354856516673298

Hann, I. H., Hui, K. L., Lee, T. S. Y, \& Png, I. P. L. (2002). Online information privacy: Measuring the costbenefit tradeoff. In the Proceedings of the 23rd International Conference on Information Systems (ICIS 2012), Barcelona, Spain.

Hoy, M. G., \& Milne, G. (2010). Gender differences in privacy-related measures for young adult Facebook users. Journal of Interactive Advertising, 10(2), 28-45. https://doi.org/10.1080/15252019.2010.10722168

Jones, W. (2008). Keeping things being found: The study and practice of personal information management. Burlington, MA: Morgan Kauffman Publishers.

Lee, J. K., \& Letho, X. (2010). E-personalization and online privacy features: The case with travel web-sites. Journal of Management and Marketing Research, 4(March), 1-14. Retrieved from http://www.aabri.com/manuscripts/09347.pdf

Lee, J. M., \& Rha, J. Y. (2016). Personalization-privacy paradox and consumer conflict with the use of locationbased mobile commerce. Computers in Human Behavior, 63, 453-462. https://doi.org/10.1016/i.chb.2016.05.056

Li, T., \& Unger, T. (2012). Willing to pay for quality personalization? Trade-off between quality and privacy. European Journal of Information Systems, 21(6), 621-642. https://doi.org/10.1057/ejis.2012.13

Kibby, M. (2009). Collect yourself. Information, Communication \& Society, 12(3), 428-443.

Kreitz, G., \& Niemelä, F. (2010). Spotify - Large scale, low latency, P2P music-on-demand streaming. In the Proceedings of 2010 IEEE Tenth International Conference on Peer-to-Peer Computing (P2P 2010), Delft, Netherlands. https://doi.org/10.1109/p2p.2010.5569963

Mahroo, A., Spoladore, D., Caldarola, E. G., Modoni, G. E., \& Sacco, M. (2018). Enabling the smart home through a semantic-based context-aware system. In Proceedings of 2018 IEEE International Conference on Pervasive Computing and Communications Workshops (PerCom Workshops) (pp. 543-548), Athens, Greece. https://doi.org/10.1109/percomw.2018.8480414 
Usage Habits in Music Streaming Applications and Their Influence on Privacy Related Issues

Malm, K. (1992). The music industry. In H. Myers (Ed.), Ethnomusicology: An introduction (pp. 349-364). London: Macmillan.

Malone, T. W. (1983). How do people organize their desks? Implications for the design of office information systems. ACM Transactions on Information Systems, 1(1), 99-112. https://doi.org/10.1145/357423.357430

Marchionini, G. (1997). Information seeking in electronic environments. Cambridge: Cambridge University Press.

Mayer, J. R. (2009). "Any person... a pamphleteer:" Internet anonymity in the age of Web 2.0. Undergraduate Senior Thesis, Princeton University, Princeton, NJ.

McCourt, T. (2005). Collecting music in the digital realm. Popular Music and Society, 28(2), 249-252. https://doi.org/10.1080/03007760500045394

Millett, L. I., Friedman, B., \& Felten, E. (2001). Cookies and Web browser design: Toward realizing informed consent online. In the proceedings of the SIGCHI conference on Human Factors in Computing Systems (CHI '01), Seattle, WA.

Milne, G. R. (2000). Privacy and ethical issues in database/interactive marketing and public policy: A research framework and overview of the special issue. Journal of Public Policy \& Marketing, 19 (1), 1-6. https://doi.org/10.1509/jppm.19.1.1.16934

Milne, G. R., \& Gordon, M. E. (1993). Direct mail privacy-efficiency trade-offs within an implied socialcontract framework. Journal of Public Policy \& Marketing, 12 (2), 206-215. https://doi.org/10.1177/074391569101200206

Milne, G. R., Rohm, A. J., \& Bahl, S. (2004). Consumers' protection of online privacy and identity. Journal of Consumer Affairs, 38(2), 217-232. https://doi.org/10.1111/j.1745-6606.2004.tb00865.x

Morris, J. W., \& Powers, D. (2015). Control, curation and musical experience in streaming services. Creative Industries Journal, 8(2), 1-17.

Nguyen, G. D., Dejean, S., \& Moreau, F. (2014). On the complemenarity between online and offline music consumption: The case of free streaming. Journal of Cultural Economics, 38(4), 315-330.

https://doi.org/10.1007/s10824-013-9208-8

Norberg, P. A., Horne, D. R., \& Horne, D. A. (2007). The privacy paradox: Personal information disclosure intentions versus behaviors. Journal of Consumer Affairs, 41(1), 100-126. https://doi.org/10.1111/j.1745$\underline{6606.2006 .00070 . x}$

Paine, C., Reips, U. D., Steiger, S., Joinson, A., \& Buchanan, T. (2007). Internet users' perceptions of 'privacy concerns' and 'privacy actions'. International Journal of Human-Computer Studies, 65(6), 526-536. https://doi.org/10.1016/j.ijhcs.2006.12.001

Sheng, H., Nah, F., \& Siau, K. (2008). An experimental study in U-commerce adoption: The impact of personalization and privacy concerns. Journal of Associations for Information Systems, 9(6), 344-376.

Snelson, C. (2011). YouTube across the disciplines: A review of the literature. MERLOT Journal of Online Learning and Teaching, 7(1), 159-169. Retrieved from http://jolt.merlot.org/vol7no1/snelson 0311.htm

Stafford, S. A. (2010). Music in the digital age: The emergence of digital music and its repercussions on the music industry. The Elon Journal of Undergraduate Research in Communications, 1(2), 112-120.

Sutanto, J., Palme, E., Tan, C. H., \& Phang, C. W. (2013). Addressing the personalization-privacy paradox: An empirical assessment from a field experiment on Smartphone users. MIS Quarterly, 37(4), 1141-1164. https://doi.org/10.25300/misq/2013/37.4.07

Swanson, K. (2013). A case study on Spotify: Exploring perceptions of the music streaming service. $M E I E A$ Journal, 13(1), 207-230. https://doi.org/10.25101/13.10

Taddicken, M. (2014). The 'privacy paradox' in the social web: The impact of privacy concerns, individual characteristics, and the perceived social relevance on different forms of self-disclosure. Journal of ComputerMediated Communication, 19(2), 248-273. https://doi.org/10.1111/jcc4.12052

Trepte, S., Teutsch, D., Masur, P. K., Eicher, C., Fischer, M., Hennhöfer, A., et al. (2015). Do people know about privacy and data protection strategies? Towards the "Online Privacy Literacy Scale" (OPLIS). In S. 
Gutwirth, R. Leenes \& P. de Hert (Eds.), Reforming European data protection law (pp. 333-365). Netherlands: Springer. https://doi.org/10.1007/978-94-017-9385-8 14

Turow, J., King, J., Hoofnagle, C. J., Bleakley, A., \& Hennessy, M. (2009). Americans reject tailored advertising and three activities that enable it. SSRN eLibrary, 1-27. https://doi.org/10.2139/ssrn.1478214

Weinberger, M., \& Bouhnik, D. (2018). Place determinants for the personalization-privacy paradox tradeoff among students. Issues in Informing Science and Information Technology, 15, 79-95. https://doi.org/10.28945/4019

Weinberger, M., Bouhnik, D., \& Zhitomirsky-Geffet, M. (2017). Factors affecting students' privacy paradox and privacy protection behavior. Open Information Science, 1(1), 1-18. https://doi.org/10.1515/opis-2017-0002

Wills, C. E. \& Zeljkovic, M. (2011). A personalized approach to web privacy: Awareness, attitudes and actions. Information Management \& Computer Security, 19 (1), 53-73. https://doi.org/10.1108/09685221111115863

Xu, H., Luo, X. R., Carroll, J. M., \& Rosson, M. B. (2011). The personalization privacy paradox: An exploratory study of decision making process for location-aware marketing. Decision Support Systems, 51(1), 42-52. https://doi.org/10.1016/i.dss.2010.11.017

\section{BIOGRAPHIES}

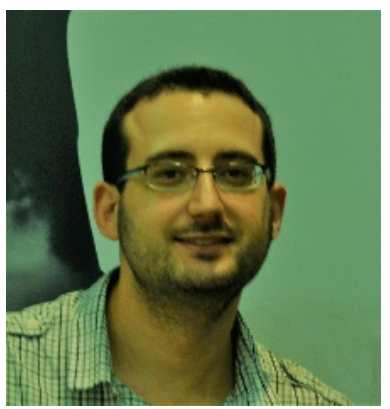

Maor Weinberger is a doctoral student at the Information Science Department in Bar-Ilan University (BIU), Israel. His professional interests include online privacy and anonymity and information security.

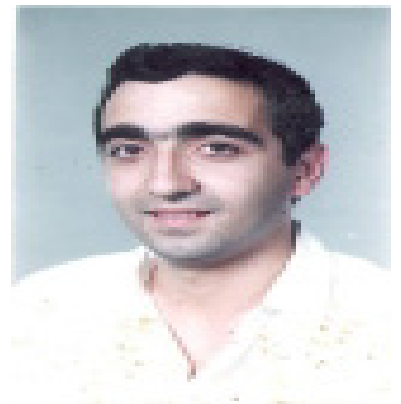

Prof. Dan Bouhnik is currently a lecturer in the Information Science department in Bar Ilan University (BIU) and in the Computer Science department in Jerusalem College of Technology (JCT) in Israel. He taught Computer Science and Logic in High Schools both in Israel and the United States. Dan is the author of a number of books used for teaching Advanced Computer Sciences in High Schools and his professional interests include virtual learning and its effect on the thinking process. 